\title{
Repositioning post partum care in Kenya
}

The Safe Motherhood Demonstration Project

Follow this and additional works at: https://knowledgecommons.popcouncil.org/departments_sbsr-rh How does access to this work benefit you? Let us know!

\section{Recommended Citation}

"Repositioning post partum care in Kenya," Safe Motherhood Policy Alert. Nairobi: Population Council, 2005. 


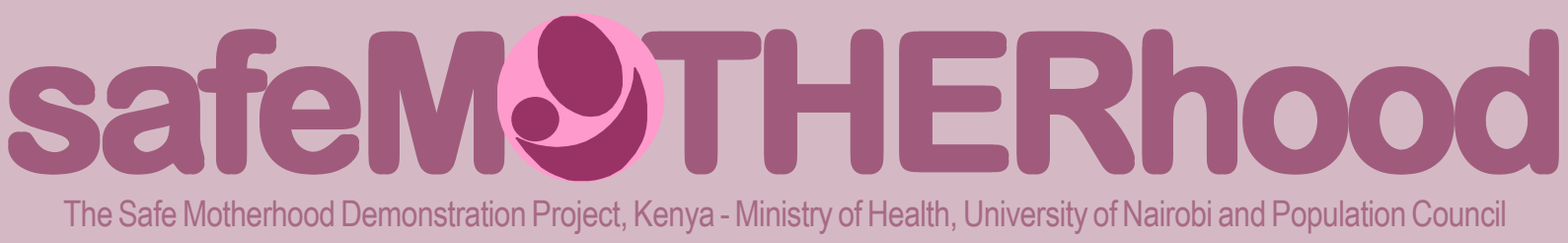

\section{Repositioning Post Partum Care in Kenya}

D espite the fact that around forty five percent of maternal deaths occur within the first 24 hours after childbirth, and over sixty five percent of maternal deaths occur during the first week of the postpartum period, ${ }^{1}$ health care providers continue to advise on a first check up at 6 weeks after childbirth. This period is also critical to newborn survival, with between 50 to $70 \%$ of life threatening newborn illnesses occurring in the first week. Yet most strategies to reduce maternal and perinatal morbidity and mortality have focused on pregnancy and birth (comprehensive antenatal care and skilled attendance at birth).

In addition to the heavy workload of providers who do not assess the mother post delivery when she may bring her infant for immunization, lack of knowledge, poverty, cultural beliefs and practices perpetuate the problem.

Men are not aware that women should attend postpartum clinic: "women do not go to clinic it is for the baby"

(Male FDG Kakamega 2003)

In Kenya, $81 \%$ of the $59 \%$ of women who deliver outside the health facility do not receive postnatal care. Only $10 \%$ of women who deliver outside a health facility attend postnatal care within 2 days, while $2 \%$ get care 3-6 days after delivery and 7\% in 7-41 days after delivery ${ }^{2}$.

If a woman delivers with a skilled attendant she is more likely to seek early postpartum care $^{3}$
Facilities do not routinely record post partum visits, the only register that exists for mothers post delivery is for family planning, thus perpetuating the lack of emphasis on the early postpartum period with no standardised register to record care given.

In an attempt to address this gap in service delivery, Population Council in conjunction with the DRH, NASCOP, University of Nairobi and other stakeholders defined the minimal services a mother and her baby should receive from a skilled attendant after birth. For the mother, three consultations are recommended: within 48 hours, within the first two weeks and again at 6 weeks. Two of these consultations are linked to the same time period for immunisations for the newborn (polio/BCG at birth, first Pentavalent immunisation at six weeks).

The first consultation includes:

Monitoring vital signs; monitoring any abnormal bleeding; pallor; physical examination; counselling and testing for HIV if not done antenatally; counselling and advice on infant feeding; infant care; self care and offer postpartum family planning. If women are HIV positive, this is an opportunity to provide continued care and support to mother and newborn.

Second consultation: Vital signs are recorded; physical examination; counselling on compliance if clients on ART or cotrimoxazole; and family planning methods.

Third consultation Repeat as for first and second visits but emphasis on uterine size; 
HIV counselling and testing if not done previously; treatment of existing conditions/ infections; family planning method selected and utilised; and screening for cancer of cervix.

A postpartum register was subsequently developed to include the care required at each of the three visits and piloted in selected facilities in Western Province.

This register has now been distributed to almost all facilities in Western Province and to hospitals in all other provinces. It is recommended that a one-day orientation to the register is carried out for health care providers to understand the importance of early postpartum care and correct recording of information.

\section{Challenges in health facilities}

- Lack of advocacy of postpartum services by health care providers

- Lack of updates / knowledge of the new schedule among providers

- Negative provider attitude towards postpartum services

- Health care providers are not aware of the policy and guidelines on early postpartum care

- Shortage of providers in health facilities

- Availability of the postpartum register in the health facilities

\section{Challenges in the Community}

- Insufficient advocacy for postpartum care at community level

- Lack of family support to postpartum mothers

- Low awareness and lack of knowledge on the importance of postpartum care

- Financial constraints

- Cultural beliefs and practices that shield the new mother and baby within their home within the first month.

\section{Policy Implications}

For Early Postpartum Care to become routine the following issues will need to be included in the RH policy:

- A clear policy directive of why Early Postpartum Care must be integrated into existing care services at health facilities

- Clear advocacy guidelines on importance of seeking early post -partum services for communities

- Involve community members and CORPS to design locally appropriate interventions

- Update Providers in Early Postpartum Care

- Personalised Focused Antenatal Care must be used as an opportunity to emphasise skilled attendance at birth and "Early Postpartum Care"

- Availability of postpartum care registers for all health facilities

- Increased workload may impact on quality of care provided

\section{Conclusion}

Early Postpartum Care must be repositioned to complete the strategies for the continuum of skilled care from Pregnancy (Focused Antenatal Care) delivery (Skilled Attendance) and after delivery (Early Postpurtum Care), with an emphasis on encouraging family spacing.

The development of a standardized postpartum register is one step towards advocating for providing Early Postpartum Care among the health service providers.

${ }^{1}$ AED, The Manoff Group, USIAD 2005 Maternal survival: improving access to Skilled Care a behaviour change approach

${ }^{2}$ Kenya Demographic Health Survey 2003

${ }^{3} \mathrm{MOH}$, Population Council, University of Nairobi, 2004 SMDP Western Province Approaches to providing quality maternity care in Kenya 